\title{
POSITIONING OF THE FEMORAL TUNNEL FOR ARTHROSCOPIC RECONSTRUCTION OF THE ANTERIOR CRUCIATE LIGAMENT: COMPARATIVE STUDY OF 2 TECHNIQUES
}

\author{
Roberto Freire da Mota Albuquerque, Marco Martins Amatuzzi, Alexandre \\ Pagotto Pacheco, Fabio Janson Angelini, Osmar Campos Jr
}

\begin{abstract}
Mota Albuquerque RF, Amatuzzi MM, Pacheco AP, Angelini FJ, Campos Jr O. Positioning of the femoral tunnel for arthroscopic reconstruction of the anterior cruciate ligament: comparative study of 2 techniques. Clinics. 2007;62(5):613-8.
\end{abstract}

OBJECTIVE: To compare the accuracy of positioning of the femoral tunnel in reconstructing the anterior cruciate ligament by means of 2 techniques: tibial tunnel and anteromedial portal.

METHOD: Femoral tunnels were drilled in 20 knees from human cadavers by means of arthroscopy. Group I had the femoral tunnel drilled via a trans-tibial tunnel, and Group II via the anteromedial portal. Four variables were measured: A) posterior wall thickness; B) tunnel positioning at the notch; C) tunnel inclination in relation to the femoral axis; and D) distance between the wire guide exit and the lateral epicondyle.

RESULTS: As above, respectively, A) $2.23 \mathrm{~mm}$ for group I and $2.36 \mathrm{~mm}$ for group II $(P=.54)$; B) $25.5^{\circ}$ for group I and $30.0^{\circ}$ for group II $(P=.23)$; C) $23.9^{\circ}$ for group I and $32.0^{\circ}$ for group II $(P=.02)$; D) $7.8 \mathrm{~cm}$ for group I and $3.9 \mathrm{~cm}$ for group II $(P<.001)$. CONCLUSIONS: Both techniques achieved the desired positioning for the femoral tunnel entrance and satisfactory thickness for the posterior cortex. Drilling via the anteromedial portal may provide greater protection against rupture of the posterior wall.

KEY-WORDS: Anterior cruciate ligament. Knee injuries. Arthroscopy. Reconstruction. Cadaver.

\section{INTRODUCTION}

Injury to the anterior cruciate ligament of the knee is a common pathological condition that leads to a high degree of morbidity, particularly in young and active patients, ${ }^{1,2}$ although it is also a problem in the elderly. ${ }^{3}$

There was a worldwide tendency to treat such patients with variations on the intra-articular reconstruction surgery described by Jones in $1963 .{ }^{4}$ With the advent of arthroscopy, intra-articular reconstruction using arthroscopic techniques have been developed and are becoming the standard access route for such surgery. ${ }^{1,5-7}$

Department of Orthopedics, Orthopedic and Traumatology Institute, Sao Paulo University, School of Medicine, Sao Paulo, SP, Brazil.

Email: rmotaa@uyol.com.br

Received for publication on April 26, 2007

Accepted for publication on June 18, 2007
One of the most important surgical steps in this technique is to determine where the femoral tunnel should be located and how to make it. ${ }^{8-10}$ This tunnel needs to be constructed in such a way as to allow the graft to be positioned as close as possible to an isometric situation during flexion and extension of the knee. ${ }^{10-15}$ The femoral tunnel position in the intercondyle notch that is considered to be most satisfactory is posterosuperior and at $30^{\circ}$ laterally to the central position of the intercondyle tunnel (11 o'clock for the right knee and 1 o'clock for the left knee). It is also recommended that its posterior wall should be $2 \mathrm{~mm}$ in thickness. ${ }^{1,5,7,16}$

Most authors using arthroscopic reconstruction have made the femoral tunnel by introducing the femoral guide through a previously constructed tibial tunnel..$^{1,5,7}$ However, some authors have used an anteromedial arthroscopic portal as an access route for introducing the guide and constructing the femoral tunnel. ${ }^{6,17,18}$ They believe that this 
modification has advantages over the classical technique. ${ }^{6,18}$ However, we have not found any experimental studies comparing these 2 techniques.

The aim of the present study was to compare the accuracy of femoral tunnel construction by means of these 2 routes.

\section{MATERIALS AND METHODS}

Our material consisted of 20 knees from 10 human cadavers without evidence of previous traumatic pathological conditions. The experiment was carried out in the Arthroscopy Laboratory of the Institute of Orthopedics and Traumatology of FMUSP

The method for obtaining the specimens consisted of an anterior longitudinal skin incision of approximately 30 $\mathrm{cm}$ in length, centered on the knee, through which circumferential dissection below the subcutaneous tissue was developed. Two transversal cuts through all the remaining structures were then performed to complete the removal of the specimen as follows: one cut $15 \mathrm{~cm}$ above the joint, with osteotomy of the femur, and the other cut $15 \mathrm{~cm}$ below the joint, with osteotomy of the tibia and fibula. Thus, the knees removed kept all their muscle and capsule-ligament structures.

Each pair of knees was identified, packed in plastic bags, and frozen at a temperature of $-20^{\circ} \mathrm{C}$. The defrosting of each pair was done in an ordinary refrigerator and started 24 hours before the arthroscopic procedure.

To perform the arthroscopic procedure, each knee was attached only by the distal femur to a bench-mounted support. Thus, the joint could be freely mobilized by manipulating the stump of the leg.

The equipment used consisted of a video-arthroscopy apparatus with an optic with a distal inclination of $30^{\circ}$ and the instruments for constructing the tunnels as follows: a cannulated drill bit of diameter $10 \mathrm{~mm}$, a guide wire for the drill bit, and 2 guides (one femoral and the other tibial) for positioning the guide wire. The femoral guide used was $7 \mathrm{~mm}$, which provides a posterior cortex of $2 \mathrm{~mm}$ when the $10-\mathrm{mm}$ drill bit is used for drilling the tunnel.

The procedure was the same for all the knees and the following sequence was used:

A) Anterolateral portal incision-a punctiform incision was made using a no. 11 blade bistoury, $1 \mathrm{~cm}$ proximally to the tibial plateau and immediately laterally to the lateral margin of the patellar tendon. Through this portal, a trochater was introduced into the joint into which water was infused and the optic at $30^{\circ}$ was connected. Inspection of the joint cavity ruled out the presence of meniscal and ligamental pathological conditions.
B) Anteromedial portal incision-a punctiform incision was made using a no. 11 blade bistoury, $1 \mathrm{~cm}$ proximally to the tibial plateau and $1 \mathrm{~cm}$ medially to the patellar tendon. The other arthroscopic instruments were introduced through this portal.

C) The anterior cruciate ligament was excised.

D) The intercondyle region and the region between the tibial spines was debrided.

The knees were divided into 2 groups as follows: Group I-Tibial tunnel route, construction of the femoral tunnel with introduction of a femoral guide by means of a previously constructed tibial tunnel; Group II-Anteromedial portal route, construction of the femoral tunnel with introduction of a femoral guide through an anteromedial portal. Group I was composed of 10 knees (5 right knees and 5 left knees). Group II was composed of the pairs for the knees in Group I.

\section{Methodology for Group I}

Construction of the tibial tunnel. The tip of the tibial guide arm was positioned just in front of the posterior cruciate ligament ( $7 \mathrm{~mm}$ anteriorly) and slightly anteriorly to the tibial spines, but displaced towards the medial tibial spine, at a point that was on a coronal straight line passing tangentially to the posterior margin of the anterior cornu of the lateral meniscus. ${ }^{1,5,7}$ The inclination between the guide and its arm was adjusted to $55^{\circ}$, and the arm was kept parallel to the tibial plateau. With the aid of an electric drill, the guide wire was introduced from a point on the tibia $1 \mathrm{~cm}$ medially to the patellar tendon, through the metaphysis until it emerged at the tibial plateau. After checking that the guide wire was well positioned, the tibial guide was removed and the tibial tunnel was drilled using the $10-\mathrm{mm}$ cannulated drill bit.

Construction of the femoral tunnel. The femoral guide was introduced through the tibial tunnel. With the knee flexed at $60^{\circ}$, the distal support for the guide was kept immediately posteriorly to the posterior cortex of the femoral intercondyle, at a $30^{\circ}$ position (11 o'clock for the right knee and 1 o'clock for the left knee). The guide wire was then introduced with the aid of an electric drill, from the superolateral region of the intercondyle until drilling into the anterolateral cortex of the femoral diaphysis, at which point the femoral guide was removed. The tunnel was drilled using a 10-mm cannulated drill bit centered on the guide wire, until reaching a depth of $30 \mathrm{~mm}$.

\section{Methodology for Group II}

Construction of the femoral tunnel. The femoral guide 
was introduced through the anteromedial portal. With the knee flexed at $115^{\circ}$, the distal support for the guide was kept immediately posteriorly to the posterior cortex of the femoral intercondyle, at a $30^{\circ}$ position (11 o'clock for the right knee and 1 o'clock for the left knee). The guide wire was then introduced with the aid of an electric drill, from the superolateral region of the intercondyle until drilling into the anterolateral cortex of the femoral diaphysis, at which point the femoral guide was removed. The tunnel was drilled using a 10-mm cannulated drill bit centered on the guide wire, until reaching a depth of $30 \mathrm{~mm}$.

In both groups, through using a 7-mm femoral guide and 10-mm cannulated drill bit, which created a tunnel with a radius of $5 \mathrm{~mm}$ centered on the guide wire, the aim was to obtain a posterior wall of thickness $2 \mathrm{~mm}$ in the femoral tunnel.

After concluding the drilling of the tunnels, the knee joints were dismantled and the femurs were dissected to remove all the soft parts, such that only the femur itself was left. Then, the femoral tunnels were studied, and 4 parameters were measured as follows: A) thickness (mm) of

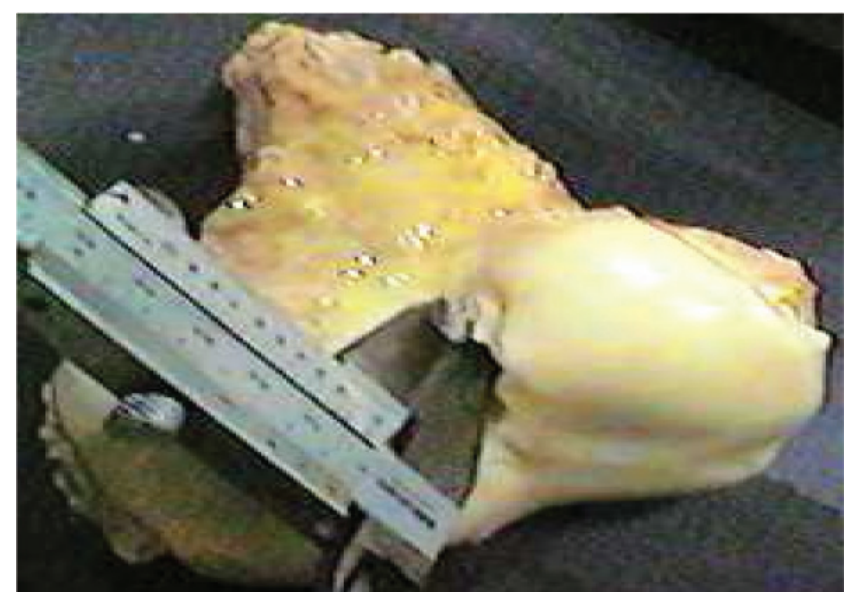

Figure 1 - Thickness of the posterior cortex

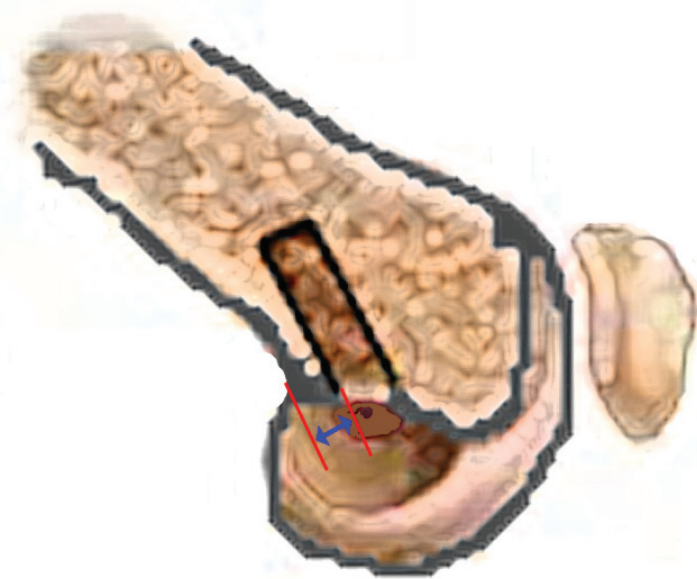

Figure 2 - Femoral sagital cut. Thickness of the posterior cortex the posterior wall of the femoral tunnel measured using pachymeter (Figures 1 and 2); B) anterior view of the positioning $\left(^{\circ}\right)$ of the tunnel entrance in the intercondyle notch (Figure 3 ); C) inclination $\left(^{\circ}\right.$ ) of the femoral in relation to the long axis of the diaphysis of the femur in the sagittal plane (Figure 4); and D) distance $(\mathrm{cm})$ between the wire guide exit (in the anterolateral cortex of the femur) and the lateral epicondyle (Figure 5).

The results were analyzed using basic statistics and compared using the Mann-Whitney $U$ method, and $P<.05$ was considered to be statistically significant.

\section{RESULTS}

The mean thickness of the posterior wall of the femoral tunnel (A) was $2.23 \mathrm{~mm}$ in Group I and $2.36 \mathrm{~mm}$ in Group II. There was no significant difference between these thicknesses $(P=.54)$, nor was there any rupturing of the posterior wall of the tunnel. The positioning of the tunnel entrance in the intercondyle (B) was at a mean of $25.5^{\circ}$ in Group I and $30^{\circ}$ in Group II. The mean inclination of the

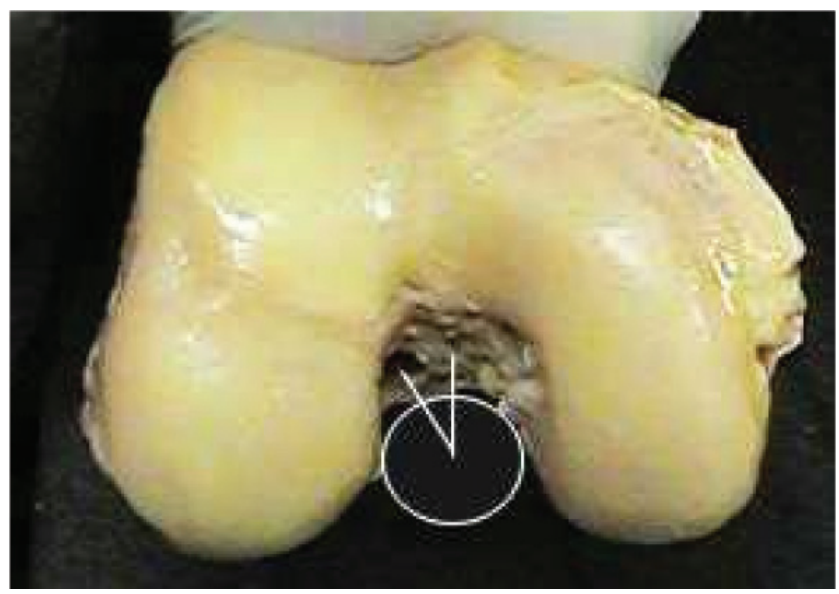

Figure 3 - Tunnel entrance in the intercondyle notch

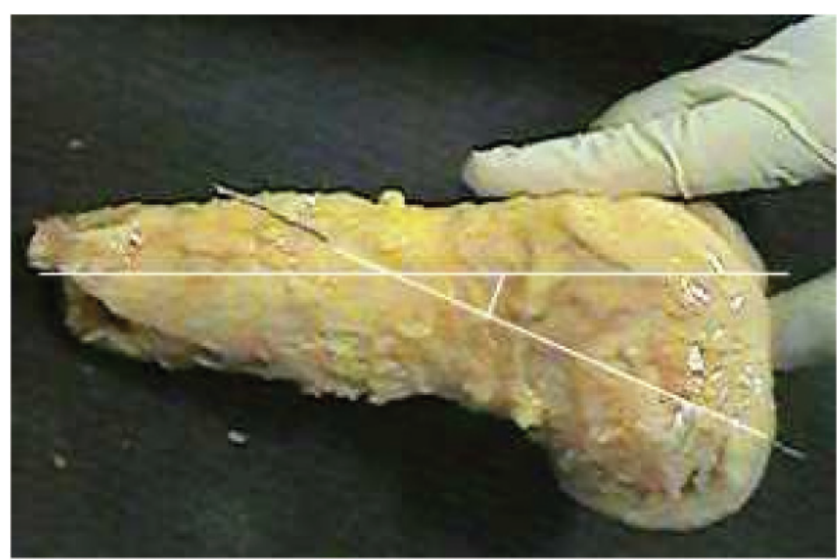

Figure 4 - Inclination of the tunnel in relation to the femoral diaphysis 


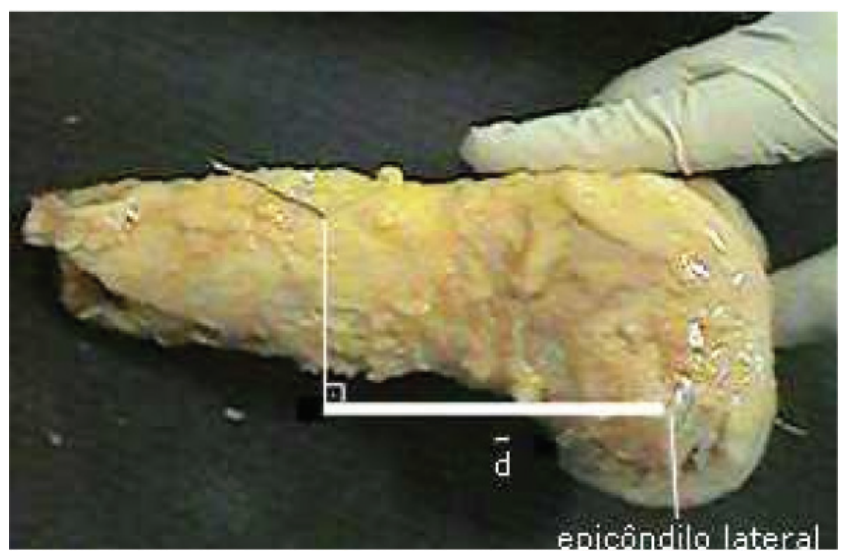

Figure 5 - Distance from the guide exit to the lateral epicondyle.

femoral tunnel in relation to the long axis of the femoral diaphysis in the sagittal plane (C) was $23.9^{\circ}$ in Group I and $32^{\circ}$ in Group II, and this difference was statistically significant $(P=.02)$. The mean distance between the guide wire exit and the lateral epicondyle (D) was $7.8 \mathrm{~cm}$ for Group I and $3.9 \mathrm{~cm}$ for Group II, and this difference was statistically significant $P<.001$ ) (Table 1).

\section{DISCUSSION}

Variability between biological specimens undoubtedly exists, as discussed by Hanley. ${ }^{19}$ Comparison between 2 surgical techniques used on different individuals may therefore give rise to a confounding factor. The validity of the comparison may also be questioned when the series analyzed are performed at different times and under different conditions, as in the series evaluated by Min et al. ${ }^{18}$ Studying the variables by means of radiographic indi- ces $^{6,17,18}$ has the advantage of being reproducible in clinical practice but cannot be as precise as direct measurement on dissected anatomical specimens.

In our study, pairs of knees from the same cadaver were used in order to eliminate the bias of variability between individuals. Furthermore, we were able to dissect each specimen and directly measure the parameters, thereby obtaining measurements of greater accuracy.

The measurements of the posterior wall thickness were similar for the 2 groups, and there were no cases of rupture of the posterior wall of the tunnel. The series evaluated by $\mathrm{O}^{\prime}$ Donnell ${ }^{6}$ had a tunnel entrance rupture rate of $82 \%$, although this did not affect the attachment of the graft. It should be emphasized that this rate was obtained after attaching the grafts using interference screws, which was not performed in our experiment. This probably explains the difference between the 2 studies, considering that attachment of the graft using interference screws subjects the tunnel to great pressure, which may cause it to rupture.

Although there was no statistically significant difference regarding the positioning of the tunnel entrance in the intercondyle notch, there seemed to be a tendency towards centralization of the femoral tunnel entrance when the tibial tunnel was used as the access route. This impression was shared by Aglietti. ${ }^{17}$ This tendency may be due to the limited choice for positioning the femoral guide in this technique, given that the choice is made according to the inclination of the tibial tunnel.

The measurements of femoral tunnel inclination in relation to the long axis of the femoral diaphysis in the sagittal plane were greater in Group II. The greater this measurement is, the greater the divergence between the tunnel and the posterior cortex is. When this divergence exists,

Table 1 - Results obtained. A= thickness of the posterior wall of the femoral tunnel, measured using pachymeter, in millimeters; $\mathrm{B}=$ anterior view of the positioning of the tunnel entrance in the intercondyle notch, in degrees; $\mathrm{C}=$ inclination of the femoral tunnel in degrees, in relation to the long axis of the femoral diaphysis in the sagittal plane; $\mathrm{D}=$ distance in centimeters between the guide wire exit in the anterolateral cortex of the femur and the lateral epicondyle.

\begin{tabular}{|c|c|c|c|c|c|c|c|c|}
\hline \multirow[b]{2}{*}{ Pair } & \multicolumn{4}{|c|}{ Group ITibial tunnel route } & \multicolumn{4}{|c|}{ Group IIAnteromedial portal route } \\
\hline & $\mathrm{A}(\mathrm{mm})$ & $\mathrm{B}(\mathrm{o})$ & $\mathrm{C}(\mathrm{o})$ & $\mathrm{D}(\mathrm{cm})$ & $\mathrm{A}(\mathrm{mm})$ & $\mathrm{B}(\mathrm{o})$ & $\mathrm{C}(\mathrm{o})$ & $\mathrm{D}(\mathrm{cm})$ \\
\hline 1 & 1.6 & 15 & 23 & 8.3 & 2.0 & 30 & 23 & 3.7 \\
\hline 2 & 2.1 & 15 & 26 & 8.1 & 2.2 & 15 & 37 & 5.6 \\
\hline 3 & 1.9 & 30 & 19 & 9.5 & 2.0 & 30 & 30 & 3.5 \\
\hline 4 & 2.8 & 15 & 25 & 8.2 & 2.3 & 30 & 27 & 3.6 \\
\hline 5 & 2.6 & 45 & 22 & 7.4 & 2.3 & 30 & 28 & 4.0 \\
\hline 6 & 2.4 & 30 & 18 & 4.8 & 2.5 & 30 & 45 & 2.1 \\
\hline 7 & 2.4 & 15 & 42 & 5.6 & 2.2 & 30 & 35 & 4.5 \\
\hline 8 & 2.3 & 30 & 32 & 7.2 & 2.5 & 30 & 30 & 6.1 \\
\hline 9 & 1.9 & 30 & 11 & 11.8 & 3.1 & 30 & 30 & 3.5 \\
\hline 10 & 2.3 & 30 & 21 & 7.5 & 2.5 & 45 & 35 & 2.5 \\
\hline Mean & 2.23 & 25.5 & 23.9 & 7.8 & 2.36 & 30 & 32 & 3.9 \\
\hline Standard deviation & 0.36 & 10.12 & 8.41 & 1.94 & 0.32 & 7.07 & 6.2 & 1.23 \\
\hline
\end{tabular}


the thickness of the posterior wall of the femoral tunnel becomes progressively greater, and consequently there is greater protection against the possibility of rupture caused by attachment using interference screws. Thus, we could infer that the greater measurements observed in Group II (anteromedial portal) should confer greater protection against rupture of the femoral tunnel. This may explain the absence of loss of graft attachment, even with the high rupture rate for the tunnel entrance wall seen in the series evaluated by O'Donnell. ${ }^{6}$

Consonant with the results relating to femoral tunnel inclination, the distance measured between the guide wire exit and lateral epicondyle was greater in Group I. This demonstrates that, with the technique used in Group II, the guide wire comes out closer to the knee, thereby making the operation easier, particularly among patients with larger thigh volumes. This result is also a consequence of the greater divergence between the femoral tunnel and posterior cortex in Group II.

These experimental results corroborate the conclusions of O'Donnell and Scerpella ${ }^{6}$ based on radiographic studies, ie, that the use of an anteromedial portal enables adequate location and orientation of the femoral tunnel without dependence on correct orientation of the tibial tunnel.

On the other hand, it was observed that it was easier to keep the femoral guide at an appropriate location in Group I, since it was supported by the surgeon's hand, the tibial tunnel, and the intercondyle notch. In Group II, the guide was supported on the intercondyle notch and the second support was provided only by the surgeon's hand. However, lack of support from the tibial tunnel provided greater free- dom for positioning the guide.

Although both surgical technique strategies were efficient in adequately positioning the graft on the joint with regard to its biomechanical behavior relative to joint stability (which was the primary objective of the procedure), the technique involving access through an anteromedial portal conferred greater protection regarding the integrity of the posterior wall of the femoral tunnel and greater freedom regarding its positioning and orientation. We believe that, even though access though a portal might not be the surgeon's initial preference, it should be considered, particularly in cases in which the surgeon faces technical difficulties in positioning the guide and the drill bit for constructing the femoral tunnel by means of transtibial access. Likewise, it should be considered in cases in which there is difficulty in achieving sufficient flexibility for enabling divergence of the tunnel from the femoral axis, with the consequent higher risk of rupture of the posterior wall.

\section{CONCLUSIONS}

Correct positioning of the entrance to the femoral tunnel (11 o'clock or 1 o'clock) and adequate thickness of the posterior cortex were obtained with both techniques.

In Group II (anteromedial portal technique), there was greater divergence between the posterior cortex and the femoral tunnel, which should provide greater protection against the possibility of rupture of the posterior wall of the tunnel.

The emergence of the guide wire in Group II was closer to the knee.

\section{RESUMO}

Mota Albuquerque RF, Amatuzzi MM, Pacheco AP, Angelini FJ, Campos Jr O. Posicionamento do túnel femoral na reconstrução artroscópica do LCA: estudo comparativo de duas técnicas. Clinics. 2007;62(5):613-8.

OBJETIVO: Comparar a acurácia do posicionamento do túnel femoral na reconstrução do ligamento cruzado anterior através de duas vias: túnel tibial e portal ântero medial.

MÉTODO: Foram perfurados túneis femorais em vinte joelhos de cadáveres humanos por via artroscópica. Grupo I: túnel femoral por acesso trans túnel tibial. Grupo II: via portal ântero-medial. Quatro variáveis foram estudadas: A) espessura da parede posterior; B) posicionamento do túnel no intercôndilo; C) angulação do túnel em relação ao eixo do fêmur; D) distância entre a saída do fio guia e o epicôndilo lateral.

RESULTADO: A) grupo I: $2,23 \mathrm{~mm}$, grupo II: $2,36 \mathrm{~mm}$ $(\mathrm{p}=0,543)$; B) grupo I: $25,5^{\circ}$, grupo II: $\left.30^{\circ}(\mathrm{p}=0,226) ; \mathrm{C}\right)$ grupo I: $23,9^{\circ}$, grupo II: $32^{\circ}(p=0,014)$; D) grupo I: 7,8 $\mathrm{cm}$, grupo II 3,9 cm (p<0,001).

CONCLUSÃO: As duas técnicas obteveram o posicionamento desejado da entrada do túnel femoral e espessura adequada da cortical posterior. A perfuração via portal ântero-medial pode propiciar maior proteção contra rotura da parede posterior.

UNITERMOS: Ligamento Cruzado Anterior. Lesões do Joelho. Artroscopia Reconstrução. Cadáver. 
1. Aglietti P, Buzzi R. Chronic anterior cruciate ligament injuries. In: Insall JN, Windsor RE, Scott WN, Kelly MA, Aglietti P. Surgery of the knee. Baltimore: Williams \& Wilkins; 1993. p. 425-504.

2. Nogalski MP, Bach BR Jr. Acute anterior cruciate ligament injuries. In: Fu FH, Harner CD, Vince KG, editors. Knee surgery. Baltimore: Williams \& Wilkins; 1994. p. 679-730.

3. Aquino MA, Leme LEG. Isokinetic dynamometry in elderly women undergoing total knee arthroplasty: a comparative study. Clinics. 2006;61:215-222.

4. Jones KG. Reconstruction of the anterior cruciate ligament. A technique using the central one-third of the patellar ligament. J Bone Joint Surg Am. 1963;45:925-32.

5. Kurzweil PR, Jackson DW. Chronic anterior cruciate ligament injuries. In: Fu FH, Harner CD, Vince KG, editors. Knee surgery. Baltimore: Williams \& Wilkins; 1994. p. 731-47.

6. O'Donnell JB, Scerpella TA. Endoscopic anterior cruciate ligament reconstruction: modified technique and radiographic review. Arthroscopy. 1995;11:557-84.

7. Spindler KP, Walker RN. General approach to ligament surgery. In: Fu FH, Harner CD, Vince KG, editors. Knee surgery. Baltimore: Williams \& Wilkins; 1994. p. 643-65.

8. Engebretsen L, Lew WD, Lewis JL, Hunter RE. Knee mechanics after repair of the anterior cruciate ligament. A cadaver study of ligament augmentation. Acta Orthop Scand. 1989;60:703-9.

9. Good L, Odenstein M, Gilquist J. Precision in reconstruction of the anterior cruciate ligament. A new positioning device compared with hand drilling. Acta Orthop Scand. 1987;58:658-61.

10. Hefzy MS, Grood ES, Noyes FR. Factors affecting the region of most isometric femoral attachments. Am J Sports Med. 1989;17:208-16.
11. Amis AA, Dawkins GPC. Functional anatomy of the anterior cruciate ligament. J Bone Joint Surg Br. 1991;83:260-7.

12. Hewson G. Drill guides for improving accuracy in anterior cruciate ligament repair and reconstruction. Clin Orthop Relat Res. 1983;(172):119-24.

13. Odensten M, Gillquist J. Function anatomy of the anterior cruciate ligament and a rationale for reconstruction. J Bone Joint Surg Am. 1985;67:257-62.

14. Penner DA, Daniel DM, Wood P, Mishira D. An in vitro study of anterior cruciate ligament and isometry. Am J Sports Med. 1988;16:238-43.

15. Schutzer SF, Christen S, Jakob RP. Further observations on the isometricity of the anterior cruciate ligament. Clin. Orthop Relat Res. 1989;(242):247-55.

16. Hoogland T, Hillen B. Intra-articular reconstruction of the anterior cruciate ligament. An experimental study of length changes in different ligament reconstructions. Clin. Orthop Relat Res. 1984;(185):197-202.

17. Aglietti P, Giron F, Baldini A. Femoral tunnel position in ACL reconstruction with three techniques: a cadaveric study. Abstract presented at the first biennial congress International Society of Arthroscopy, Knee Surgery and Orthopaedic Sports Medicine, May 1116, 1997. Arthroscopy. 1998;14:S15.

18. Min BH, Kim HS, Kim SJ. Modified anterior cruciate ligament reconstruction: femoral tunnel preparation through the anteromedial portal. Abstract presented at the first biennial congress International Society of Arthroscopy, Knee Surgery and Orthopaedic Sports Medicine, May 11-16, 1997. Arthroscopy. 1998;14:S16.

19. Hanley P, Lew WD, Lewis JL, Hunter RE, Kirstukas S, Kowalczyk C. Load sharing in augmented composite ACL grafts. Am J Sports Med. 1989;17:414-22. 